\title{
Electronic language: A study of word processing by emotionally disturbed children and adolescents in residential treatment
}

\author{
D. PATRICK ZIMMERMAN \\ University of Chicago, Chicago, Illinois
}

\begin{abstract}
The word-processing language use of a small group of severely emotionally disturbed children and adolescents was compared with their handwritten productions. A content analysis based on a total sample of 4,112 words was performed to explore the thematic and structural language differences between the two writing modes. The findings indicate that the computer-mediated writing tended to improve some aspects of thematic expression, while the handwritten mode was preferable for certain structural characteristics.
\end{abstract}

In recent years, a great deal has been written about the possible impact of computer involvement upon youth. These commentaries have taken a number of forms, including: (1) partisan and polarized academic speculation, (2) naturalistic observations, and (3) experimental or quasi-experimental research. With regard to the first type of position, a number of writers have contended that computer involvement will have a more critical and widespread impact upon youth than any other technological development achieved during the last century (Deken, 1982; Evans, 1979; Heim, 1987; Lepper, 1982; Turkle, 1984; Vallee, 1982). Of this group, the proponents of computer involvement claim that the effects of this technology upon youth will be positive, stimulating a greater motivation to learn, enabling an easier understanding of certain powerful ideas, and yielding an increase in selfesteem along with heightened feelings of independence (Lepper, 1982; Papert, 1980). Critics, however, are equally convinced that computer use will endanger human creativity, natural language, contemplative thought, and our sense of culture. Furthermore, some critics warn that computer involvement may well lead some youths to become socially and emotionally constricted, impulsive, and, ultimately, sociopathic (Davy, 1984; Sardello, 1984; Simpson, 1984).

As one example of naturalistic observation, Turkle (1984) based her conclusions about user-computer interactions on long-term observations of children and adolescents involved with computerized toys, video games, and programming activities. Rather than emphasizing positive or negative effects of computers on youths, Turkle focused on the emotionally evocative powers of the computer. From her observations, she conceptualized a framework for thinking about the range of psychological relationships that people appear to establish with computers. She

The author's address is: The Sonia Shankman Orthogenic School, University of Chicago, Chicago, IL 60637. described metaphysics (concerns about whether computers think, feel, are alive, etc.), mastery, and identity as three nonexclusive modes of relating to computers. Furthermore, these modes were seen not simply as dominant themes in child and adolescent development with respect to computers, but were also described as dominant themes in the emergence of different computer groups or cultures (metaphysics in the world of artificial intelligence, mastery for the "hacker," and identity for the home computer owner).

The third type of commentary, based upon experimental or quasi-experimental research, has focused mainly on the instrumental influences of computers upon youth in the area of computer-assisted instruction. This research has attempted to evaluate educational gains, learning retention, on-task behaviors, and the advantages of specific system characteristics. However, attempts to study empirically the broader issues of the psychological effects and social influence of computers upon youth have until now been largely neglected.

Computer-mediated communication has been described as one of the more powerful components of computer technology (Vallee, 1982). A review of the current literature, however, revealed only a few references to its impact on youth. Erdman, Klein, and Greist (1983) compared computer and handwritten interviews of high school students. They found that although the two methods appeared to collect similar data, the computer interview seemed to evoke more positive subject evaluations and more complete information. In a previous study, I compared the computer-conferencing language use of emotionally disturbed adolescents with transcripts of their face-to-face small-group verbal communications (Zimmerman, 1987). A content analysis of the two communication modes revealed that the computer-conferencing language was slightly more self-referent, was accompanied by a lower level of tension, was more expressive of feelings, and made more frequent references to interpersonal issues than did face-to-face communications. Furthermore, the 
computer-mediated language reflected a more positive object-relations stance, was less negative in expressive style, and appeared to diminish certain traditional gender differences in group communication.

In addition to computer interviewing and electronic conferencing, word processing is one of the more powerful and widely used forms of computer communication. A recent review of the literature found no references to empirical studies that investigated the psychological effects of computer word processing on either youths or adults. In his recent theoretical study of word processing, however, Heim (1987) constructed an elaborate, though speculative, critique of word processing, or the "word in process," as he describes it.

First, Heim (1987) pointed out some of the obvious advantages of word processing. For example, with the removal of the drudgery of physical writing, word processing promises to be a liberating force, affording unprecedented speed and convenience to the writer. Unfortunately, according to Heim, word processing also has negative effects on writers. The human being, in his view, undergoes a transformation in the "felt sense" of time during interface with the computer. The acceleration of the sense of time experienced in word processing can be one contributing factor to a sense of stress currently described as "technostress" (Brod, 1984). This syndrome, a pathology specifically ascribed to the computer revolution, is further detailed as: (1) the internalization of standards by which computers work-accelerated time, (2) a desire for mastery and perfection, (3) yes/no patterns of thinking, and (4) a reduced ability to perform creatively or in a loving way. Technostress is defined as a modern disease of maladaptation, of overidentification with computers. According to Heim, stress has become the prevalent pathology of our time, just as hysterical neurosis was the predominant pathology of Freud's first explorations.

In Heim's (1987) view, the model of intelligence associated with word processing emphasizes a thoroughgoing productivity where ideational flow is stressed over thought gestation and concentration, inner thought is foreshortened, and the sense of immediacy is valued. According to Heim, while immediacy leads to a greater abundance of material, the productions are less refined, civil, or polite. Computer word processing, in Heim's assessment, results in writing that is more informal, vulgar, and less evocatively creative. The glut of text produced is frequently fragmented and incoherent, rather than associated with an integrated sense of intelligence. According to Heim, word processing manifests truth destabilized, where the possibility of copious profusion means that what is written is not chosen deeply, authentically, or existentially. He further asserts that the volatility of the electronic element insures that the felt sense of truth is undermined. Aside from Heim's cogent and extensive critique of word processing, however, little is actually known about its effects upon thought and language use, since the literature reveals no empirical studies of its social or psychological impact.

\section{THE STUDY}

Electronic communication is one of the most powerful aspects of modern computer technology, and word processing is the most widely utilized component of computer-mediated communication. In an attempt to measure the possible extent of its social and psychological effects upon youth, I compared the word-processing communications of 7 emotionally disturbed children and adolescents with samples of their handwritten language production.

The comparison was based on a content analysis of each type of text, using the Harvard IV Psychosociological Dictionary (1973) as the content analysis tool. The Harvard IV Dictionary contains 104 primary and secondary consensually validated thematic categories. Using this dictionary, I attempted to specify the differences between computer-processed and handwritten language in a number of thematic areas, including concrete objects, the natural world, psychological states, behavioral processes, social institutions, interpersonal concerns, object-relations stance, ascribed role status, and expressive styles (Dunphy, Bullard, \& Crossing, 1973; Rochester, 1980; Stone, Dunphy, Smith, \& Ogilvie, 1966). Comparative measures were also made with regard to the degree of stress/anxiety, egocentricity, and idiosyncratic word usage.

\section{METHOD}

\section{Subjects}

The study was conducted at the Sonia Shankman Orthogenic School of the University of Chicago. The school provides special education services and long-term psychoanalytically oriented residential treatment for severely emotionally disturbed children and adolescents (Bettelheim, 1950, 1955, 1967, 1974; Sanders, 1985, 1989). Seven students, 6 males and 1 female, were included in the study. Their ages ranged from 7 to 20 years, with an average age of 13.3 years. The students presented serious psychopathology; prior to their referrals to the Orthogenic School, psychiatrists had diagnosed 6 as schizophrenic and 1 as a borderline personality.

\section{Procedure}

System usage. The students were involved in an 8week-long word-processing project, using Apple Пle computers and the Homeword word-processing program. Each student was scheduled to work with the computer for word processing once a week; each session lasted 30 $\mathrm{min}$. The students were informed at the beginning of the project that there were no constraints regarding their use of language, grammar, or subject matter. The roles of the researcher and the computer instructor were limited to technical matters and to the facilitation of system use.

Data analysis. All computer-mediated writing was printed out at the end of each computer session. For every session, the first 50 words (or the total production, if less 
than 50 words) written by each student was used for analysis and was combined at the conclusion of the project for use as one set of data. In addition, during the course of the project, participants were asked to produce a similar handwritten sample in their classrooms each week. As in the computer-mediated mode, students were advised that there were no constraints upon their writing in terms of subject matter, grammar, or language use. Again, the first 50 words or less of each handwritten production were combined for use as the second set of data. These procedures were similar to those reported in other content analysis studies of verbal behavior of emotionally disturbed subjects (Maher, McKean, \& McLaughlin, 1966; Oxman, Rosenberg, \& Tucker, 1982; Rochester, 1980; Rosenberg \& Tucker, 1979; Tucker \& Rosenberg, 1975).

Each set of data (the record of word-processing writings [2,034 words] and the typescript of handwritten classroom productions [2,078 words]) was analyzed by both qualitative and exploratory quantitative content analysis, using the Harvard IV Dictionary.

\section{RESULTS}

\section{Thematic Differences}

As in previous studies using the Harvard IV Diction$a r y$, thematic category (tag) index scores were derived by dividing the frequencies of the category assignments by the total number of words in each sample, and multiplying the quotient by 1,000 . Index ratios between the two writing modes were then computed. The first-order category differences between the two writing modes are presented in Table 1. This table (and Table 2, which follows) lists only the tags that met two levels of difference: (1) the index ratio between the samples, rounded to tenths, must have equaled or exceeded 1.5, and (2) at least one of the two samples must have produced the tag a minimum of 10 times. This eliminated all index ratios that were high, but were dependent upon very low absolute raw frequencies. Index ratios that met these criteria are referred to as "high index ratios."

Table 1 illustrates a number of thematic differences between the computer word-processing and the handwritten modes. First, the computer mode was noticeably less focused upon the realm of concrete objects. Handwritten productions, on the other hand, were much more concrete, with high index ratios for six of the concrete object tags (NATURAL OBJECT, REGION, ANIMAL, BODY PART, HUMAN COLLECTIVE, and OUR). While this suggests a greater interest in living things for the handwritten mode, it also displays a shift away from perceptions about distinctly independent humans (high ratio for ANIMAL) toward a somewhat more dependent, associative position with regard to others in the environment (high index ratios for HUMAN COLLECTIVE, OUR). The handwritten communications of these children and adolescents also conveyed a significant degree of bodily concern (high index ratio for BODY PART). The wordprocessing language, on the other hand, emphasized the
Table 1

A Comparison of First-Order Thematic Tags in Word-Processing and Handwritten Language Use Among Emotionally Disturbed Children and Adolescents $(N=7)$

\begin{tabular}{|c|c|c|c|}
\hline \multicolumn{2}{|c|}{ Word Processing } & \multicolumn{2}{|l|}{ Handwritten } \\
\hline Tag & $\begin{array}{l}\text { Index } \\
\text { Ratio }\end{array}$ & Tag & $\begin{array}{l}\text { Index } \\
\text { Ratio }\end{array}$ \\
\hline \multicolumn{2}{|l|}{ Concrete Objects } & \multicolumn{2}{|l|}{ Concrete Objects } \\
\hline Tool & 1.7 & Natural Object & 1.7 \\
\hline Vehicle & 2.4 & Region & 1.8 \\
\hline \multirow[t]{2}{*}{ Pronoun: You } & 1.7 & Animal & 2.6 \\
\hline & & Body Part & 11.8 \\
\hline \multicolumn{2}{|c|}{ Psychological States } & Human/Collective & 1.6 \\
\hline Need & 1.9 & Pronoun: Our & 1.5 \\
\hline Know & 1.8 & & \\
\hline \multirow[t]{2}{*}{ Virtue } & 1.9 & Psychological States & \\
\hline & & Means & 1.7 \\
\hline \multicolumn{4}{|l|}{ Behavior } \\
\hline \multirow[t]{2}{*}{ Exert } & 2.0 & Natural World & \\
\hline & & Vary & 1.9 \\
\hline \multicolumn{2}{|l|}{ Natural World } & Frequency & 3.3 \\
\hline Time & 1.5 & Relation & 1.8 \\
\hline Quality & 2.4 & & \\
\hline
\end{tabular}

more practical, instrumentally useful kinds of concrete objects (high index ratio for TOOL, VEHICLE), and indicated a more direct expression of relationship to others (high ratio for YOU).

In the general areas of emotion, cognition, and the positive aspect of evaluation (high ratios for NEED, KNOW, and VIRTUE), computer word processing emphasized a greater number of psychological states than did the handwritten samples. The students' handwritten communications had a high ratio for only one psychological category, denoting objects, acts, or methods utilized in achieving goals (MEANS). This tendency for computer-mediated communication to be more expressive of psychological themes has been noted elsewhere (Zimmerman, 1987).

Word-processing language emphasized only one behavioral category (high ratio for EXERT) that indicates assertive, aggressive, or violent actions toward people or objects. The handwritten mode was high for none of the behavioral tags, which suggests a somewhat more passive stance with regard to most of the subcategories of communication and action included in this domain.

Of the tags that are descriptive of the natural world, word-processing language emphasized references to time and duration (high ratio for TIME) and words that indicate qualities or degrees of qualities (high ratio for QUALITY). Handwritten language, on the other hand, emphasized expressions of change, frequencies or reoccurrences, and abstract relationships between people, places, objects, and ideas (high ratios for VARY, FREQUENCY, RELATION).

The second-order tags, which usually add further elaboration to the first-order tag assignments, described five factors: the interpersonal axes, the Osgood Semantics Differential Scale (object-relations stance), ascribed status, communication style, and institutions. Table 2 compares the high thematic index ratios of the second-order 
Table 2

A Comparison of Second-Order Thematic Tags

in Word-Processing and Handwritten Language Use

Among Emotionally Disturbed Children and Adolescents $(N=7)$

\begin{tabular}{lccc}
\hline \multicolumn{2}{c}{ Word Processing } & \multicolumn{2}{c}{ Handwritten } \\
\hline \multicolumn{1}{c}{ Tag } & $\begin{array}{c}\text { Index } \\
\text { Ratio }\end{array}$ & & $\begin{array}{c}\text { Index } \\
\text { Ratio }\end{array}$ \\
$\begin{array}{l}\text { Ascribed Status } \\
\text { Female }\end{array}$ & 3.7 & & $\begin{array}{c}\text { Ascribed Status } \\
\text { Male }\end{array}$ \\
Style & & Style & 1.7 \\
Overstate & 1.5 & Understate & 1.5 \\
Institutions & & Negate & 1.5 \\
Military & 2.6 & Institutions & \\
& & Academic & 2.4 \\
& & Economic & 2.5 \\
\hline
\end{tabular}

tags, which differentiated between the computer and handwritten modes for only three of the five scales.

Neither the word-processing nor the handwritten mode had a high index ratio for any of the interpersonal tags (AFFILIATIVE, HOSTILE, POWER, SUBMISSIVE), although the computer communications tended to be somewhat more affiliative (AFFILIATIVE, index ratio $=1.4$ ), which connotates a somewhat greater degree of affiliation or supportiveness. The Osgood Semantics Differential tag indexes, which suggest object-relations stance, also appeared to be generally similar (ACTIVE, PASSIVE, POSITIVE, NEGATIVE, STRONG, WEAK) in both writing modes. Word-processing language, however, was somewhat more positive, which implies a more positive object orientation (POSITIVE, index ratio $=1.4$ ).

With regard to ascribed status, the computer-mediated mode was high for the female role (FEMALE), while the handwritten language emphasized the male role (high index ratio for MALE). Family and adult/nonadult considerations were relatively insignificant (KIN, NONADULT), and racial considerations were absent (RACE) in both communication modes.

The communication style categories describe kinds of defensiveness in communication. Handwritten language appeared to be more defensive, with high index ratios for two of the three categories (UNDERSTATE, NEGATE). UNDERSTATE indicates a tendency to deemphasize and withdraw in communication, while NEGATE implies denial and opposition. Word-processing language had a high ratio for one of the categories (OVERSTATE), which suggests a tendency to overemphasize and exaggerate in communication.

In terms of institutional concerns, there was no noticeable difference between the two writing modes with regard to four of the seven institutional categories (EXPRESSIVE, LEGAL, POLITICAL, RELIGIOUS). The handwritten language, however, emphasized academic, intellectual, and educational matters (high index ratio for ACADEMIC), as well as words related to financial and commercial matters (high ratio for ECONOMIC). Word-processing communications, on the other hand, made more frequent reference to words related to military matters (high index ratio for MILITARY).

\section{Structural Differences}

Type-token ratio. The type-token ratio (TTR) is obtained by dividing the total number of first-order tags by the total number of words tagged in each sample. Previous research has suggested that lower TTRs are associated with more pathological and cognitively disorganized subjects (Fairbanks, 1944; Lorenz \& Cobb, 1954; Maher et al., 1966; Mann, 1944; Whitehorn \& Zipf, 1943). Rounded to hundredths, the TTRs for the computer wordprocessing and handwritten texts were identical (.04).

"Leftovers" (words that received no first- or secondorder tag) were examined to determine whether a higher percentage of unassignable or less common words was being used in either of the samples. The results showed that the percentage of words that could not be tagged was identical for the two samples (37\%). Of the leftovers, $9 \%$ in the computer sample and $12 \%$ in the handwritten sample were proper names. These findings suggest that the word-processing and handwritten samples did not differ substantially in the range of different words employed.

Egocentricity index. Another popular structural language comparison has been the degree of egocentricity, as measured by the frequency of self-referring pronouns (Maher et al., 1966). Previous studies have reported that normal subjects made more references to the self than did disorganized or schizophrenic subjects (Lorenz \& Cobb, 1954; Mann, 1944). The more frequent self-references by normal subjects seemed to be a reflection of a greater interest in themselves and their own lives. In the present study, the index score of the SELF tag represented the index score for self-referring pronouns. Computer word processing was somewhat less egocentric (index score = 65.39 ; index ratio $=.91$ ) than was the handwritten sample (index score $=72.19$; index ratio $=1.10$ ).

Distress-relief quotient. The distress-relief quotient (DRQ) has been used to measure differences in levels of tension or anxiety in language use (Dollard \& Mowrer, 1947). The DRQ is obtained by computing the ratio of "distress" themes to "relief" themes, as defined by the Harvard IV Dictionary (Maher et al., 1966). Two meaures were made of the DRQ, using the feeling (emotion) categories. One measure consisted of the frequency of words in the NEED and PAIN categories, divided by the sum of the frequencies in the NEED, PAIN, and PLEASURE categories. The second ratio consisted of the frequency of words in the AROUSAL category, divided by the sum of the frequencies in the AROUSAL and PLEASURE categories. The results of both of these measures are shown in Table 3.

It should be noted that, by either index, the computer word-processing language had a higher DRQ than did the handwritten samples, which indicates a higher degree of stress or tension underlying the former mode of writing. This finding differs from results reported in earlier investigations of computer versus handwritten interviewing 
Table 3

A Comparison of Tension Levels in Word-Processing (Computer) and Handwritten (Hand) Communications

Among Emotionally Disturbed Children and Adolescents $(N=7)$

\begin{tabular}{|c|c|c|c|c|}
\hline Thematic Categories & Computer $F$ & Index & Hand $F$ & Index \\
\hline Need + Pain & 18 & 8.85 & 10 & 4.74 \\
\hline Need + Pain + Pleasure & 25 & 12.29 & 19 & 9.0 \\
\hline DRQ (1) & \multicolumn{2}{|l|}{.72} & \multicolumn{2}{|c|}{.53} \\
\hline Arou & 42 & 20 & 39 & 18. \\
\hline Arousal + Pleasure & 49 & 24.09 & 48 & 23. \\
\hline DRQ (2) & \multicolumn{2}{|l|}{.86} & \multicolumn{2}{|c|}{.81} \\
\hline
\end{tabular}

Note-DRQ $=$ distress-relief quotient (Dollard \& Mowrer, 1947).

(Canoune \& Leyhe, 1985) and computer conferencing versus face-to-face communication (Zimmerman, 1987).

\section{DISCUSSION}

Some writers have contended that computer involvement by youth will ultimately lead to affective withdrawal, mechanistic thinking, and sociopathic behavior. With particular reference to computer word processing, Heim (1987) has warned that this form of computer use will lead to the internalization of an accelerated sense of time and a pathological sense of stress, described as technostress. Furthermore, he has suggested that a sense of immediacy will come to be valued at the expense of inner thought. Finally, Heim has predicted that word processing will ultimately be responsible for a level of writing that is more fragmented and incoherent, as well as less creative than traditional communication. While the findings of this exploratory study of word processing cast doubt upon the catastrophic tone of Heim's concerns, they do suggest that there may be substance to some of his speculations about the effects of word processing upon language.

First, word-processing language in this study tended to be less concretely oriented than the handwritten samples. Word processing had high ratios for categories that represent a direct relationship to others and for practical, instrumental objects, whereas the handwritten mode had high ratios for twice as many categories that denote concrete objects. In the handwritten mode, human groups were preferred over perceptions of distinct and separately functioning individuals. In fact, there was some suggestion of a withdrawal from strictly human perceptions. In addition, the handwritten language expressed a notably higher degree of bodily concern than did the computermediated mode.

Second, the word-processing mode was more expressive of psychological states, with high index ratios in the areas of emotion, cognition, and positive evaluation. Handwriting had high ratios only for the sometimes manipulative psychological category (MEANS), which denotes objects or methods utilized in attaining goals.

Third, with respect to behavior, word-processing language emphasized assertive, even aggressive action, while handwritten language tended to be less action-oriented.
This may imply some support for Heim's (1987) assertion that word processing emphasizes production, while handwriting is associated with a greater reliance upon inner thought.

Fourth, in terms of tags that describe natural world dimensions, the handwritten mode tended to emphasize quantitative elements (expressions of change, frequency, or reoccurrences), while computer word processing had high ratios for qualitative aspects. The computer productions, however, also emphasized words that describe time and duration, which under further investigation could lend support to Heim's (1987) contention that word processing alters the sense of time as we usually know it.

Fifth, with regard to the second-order tags, wordprocessing language emphasized an interest in female issues, in contrast to the tendency of the handwritten samples to exhibit a male-dominated orientation. Word processing also tended to be more socially affiliative and supportive, with higher positive measures of objectrelations stance. While the computer mode used a more exaggerated communication style, handwritten language was more defensive, tending to underestimate, oppose, and deny. Word processing was concerned with the more aggressive military institution, while handwritten productions tended to identify with scholastic and acquisitive, financial issues.

Finally, measures of structural characteristics showed that word usage in the computer mode was neither more impoverished nor less conventional than in the handwritten setting. Computer word-processing language, however, was less self-referent, which suggests that it might be both less inner-directed and more disorganized than handwritten communication. Word-processing language was also accompanied by a higher level of tension and stress. These findings may lend some preliminary support to Heim's (1987) concerns that word processing diminishes the use of inner thought, produces more disorganized language, and leads to a greater felt sense of stress.

\section{CONCLUSION}

The present study reveals communication characteristics in computer word processing that suggest that, for seriously emotionally disturbed youths, this use of the computer might be a helpful adjunct in both special education and milieu treatment activities. Possible therapeutic factors include a heightened sensitivity to psychological themes, the use of less concrete language, a more assertive stance toward others, a greater interest in qualitative dimensions of the environment, and a somewhat more positive object-relations stance. Other factors, however, suggest a need for further investigation of the possibly negative aspects of word-processing communication, including fewer references to the self (which suggests increased disorganization), a preoccupation with issues of time and duration (which suggests a possibly altered sense of time), and an increased felt sense of tension and stress. 


\section{REFERENCES}

Bettelheim, B. (1950). Love is not enough. Glencoe, IL: Free Press. Bettelheim, B. (1955). Truants from life. Glencoe, IL: Free Press. Bettelheim, B. (1967). The empty fortress. New York: Free Press. Bettelheim, B. (1974). A home for the heart. New York: Alfred A. Knopf.

BroD, C. (1984). Technostress: The human cost of the computer revolution. Reading, MA: Addison-Wesley.

Canoune, H. L., \& Leyhe, E. W. (1985). Human versus computer interviewing. Journal of Personality Assessment, 49, 103-106.

Davy, J. (1984). Mindstorms in the lamplight. Teachers College Record, 85, 631-639

Deken, J. (1982). The electronic cottage. New York: Morrow.

Dollard, J., \& Mowrer, O. H. (1947). A method of measuring tension in written documents. Journal of Abnormal \& Social Psychology, 42, 3-32.

Dunphy, D. C., Bullard, C. G., \& Crossing, E. E. M. (1973). Validation of the General Inquirer Harvard IV Dictionary. Unpublished report. Harvard University, Department of Social Relations, Cambridge, MA.

Erdman, H., Klein, M. H., \& Greist, J. H. (1983). The reliability of a computer interview for drug use/abuse information. Behavior Research Methods \& Instrumentation, 15, 66-68.

Evans, D. (1979). The micro millenium. New York: Viking.

FaIRBANKs, H. (1944). The quantitative differentiation of samples of spoken language. Psychological Monographs, 56, 19-28.

HARVARD IV PSYCHOSOCIOLOGICAL DICTIONARY. (1973). (Unpublished dictionary). Harvard University, Department of Social Relations, Cambridge, MA

HeIm, M. (1987). Electric language: A philosophical study of word processing. New Haven: Yale University Press.

LEPPER, M. F. (1982, August). Microcomputers in education: Motivational and social issues. Paper presented at the 90th annual meeting of the American Psychological Association, Washington, DC.

LORENZ, M., \& COBB, S. (1954). Language patterns in psychotic and psychoneurotic subjects. Archives of Neurological Psychiatry, 72, 665-673.

Maher, B. A., McKean, K. O., \& Mclaughlin, B. (1966). Studies in psychotic language. In P. J. Stone, D. C. Dunphy, M. S. Smith, \& D. M. Ogilvie (Eds.), The General Inquirer: A computer approach to content analysis (pp. 469-503). Cambridge, MA: MIT Press.

ManN, M. B. (1944). The quantitative differentiation of samples of written language. Psychological Monographs, 56, 41-74.

Oxman, T. E., Rosenberg, S. D., \& Tucker, G. J. (1982). The language of paranoia. American Journal of Psychiatry, 139, 275282.

PAPERT, S. (1980). Mindstorms: Children, computers, and powerful ideas. New York: Basic Books.

Rochester, S. (1980). Thought disorder and language use in schizophrenia. In R. W. Reiber (Ed.), Applied psycholinguistics and mental health (pp. 11-67). New York: Plenum.

RosenberG, S. D., \& TUCKer, G. J. (1979). Verbal behavior and schizophrenia: The semantic dimension. Archives of General Psychiatry, 36, 1331-1337.

SANDERs, J. (1985). The Sonia Shankman Orthogenic School: Psychodynamic milieu therapy in an educational residential setting. International Journal of Therapeutic Communities, 6, 181-189.

SANDERS, J. (1989). A greenhouse for the mind. Chicago: University of Chicago Press.

SARDELlo, R. J. (1984). The technological threat to education. Teachers College Record, 85, 549-558.

Simpson, B. (1984). Heading for the ha-ha. Teachers College Record, $85,622-630$.

Stone, P. J., Dunphy, D. C., Smith, M. S., \& OGilvie, D. M. (1966). The General Inquirer: A computer approach to content analysis. Cambridge, MA: MIT Press.

TuCKer, G. J., \& Rosenberg, S. D. (1975). Computer content analysis of schizophrenic speech: A preliminary report. American Journal of Psychiatry, 132, 611-616.

TuRKLE, S. (1984). The second self. New York: Simon \& Schuster.

VALLEE, J. (1982). The network revolution. Berkeley, CA: And/Or Press.

Whitehorn, J., \& ZIPF, G. (1943). Schizophrenic language. Archives of Neurological Psychiatry, 49, 831-851.

Zimmerman, D. P. (1987). Effects of computer conferencing on the language use of emotionally disturbed adolescents. Behavior Research Methods, Instruments, \& Computers, 19, 224-230. 